\title{
Removal of direct blue 129 from aqueous medium using surfactant-modified zeolite: a neural network modeling
}

\author{
Mahmoud Zarei $^{1^{*}}$, Nader Djafarzadeh ${ }^{2}$, Leila Khadir ${ }^{3}$ \\ ${ }^{1}$ Research Laboratory of Environmental Remediation, Department of Applied Chemistry, School of Chemistry, University of Tabriz, \\ Tabriz, Iran \\ ${ }^{2}$ Department of Chemistry, Miyaneh Branch Islamic Azad University, Miyaneh, Iran \\ ${ }^{3}$ Department of Chemical Engineering, Ahar Branch, Islamic Azad University, Ahar, Iran
}

\begin{abstract}
Background: Conserving water for human survival and providing future security are important issues that need to be addressed.

Methods: In this study, a zeolite modified with hexadecyl trimethyl ammonium bromide (HDTMA-Br), a cationic surfactant, and its application in removing direct blue 129 (DB129) was examined. Fourier transform infrared spectroscopy (FT-IR) and scanning electron microscopy (SEM) were used to characterize both modified and unmodified zeolites. The effects of operational parameters such as the amount of adsorbent, initial dye concentration and $\mathrm{pH}$ on the removal efficiency of the dye were examined.

Results: The results showed that in the initial dye concentration of $50 \mathrm{mg} / \mathrm{L}$, the optimum amounts of adsorbent and $\mathrm{pH}$ were $0.3 \mathrm{~g}$ and 7, respectively. Increasing the dye concentration from 20 to $100 \mathrm{mg} / \mathrm{L}$ resulted in the reduction of the removal efficiency from $100 \%$ to $79 \%$ in the contact time of 90 minutes. The results indicated the highest attracting correlation with Langmuir model. The maximum adsorbent capacity obtained from Langmuir model was $25 \mathrm{mg} / \mathrm{g}$. The kinetics of the dye adsorption on the modified zeolite followed pseudo-second-order kinetics model. Calculated thermodynamic parameters showed that Gibbs free energy changes (DGo) at temperatures of 20 and $45^{\circ} \mathrm{C}$ were -29.41 and $-35.20 \mathrm{~kJ} / \mathrm{mol}$, respectively. Enthalpy (DHo) and entropy changes were equal to $41.181 \mathrm{~kJ} / \mathrm{mol}$ and $0.241 \mathrm{~J} / \mathrm{mol} \mathrm{K}$, respectively. The results showed that the processing was a spontaneous endothermic reaction. The process modeled by artificial neural networks (ANN) showed that the experimental results can be accurately modeled using neural network model. The correlation coefficient found between the experimental and the model results was 0.951 .

Conclusion: Due to the low cost, high abundance and availability of zeolite, the removal efficiency of this adsorbent can be increased to desirable levels by modifying.

Keywords: Zeolite, Adsorption, Kinetics, Thermodynamics, Neural networks

Citation: Zarei M, Djafarzadeh N, Khadir L. Removal of direct blue 129 from aqueous medium using surfactant-modified zeolite: a neural network modeling. Environmental Health Engineering and Management Journal 2018; 5(2): 101-113. doi: 10.15171/EHEM.2018.15.
\end{abstract}

Article History:

Received: 20 April 2018 Accepted: 3 June 2018

ePublished: 29 June 2018

\section{Introduction}

Simultaneous with the growth of human populations, communities, science and technology, new horizons are being reached in our world. But this growth is associated with high costs. Disturbed and disordered environment associated with severe pollution are among the consequences of this rapid growth. In addition to other requirements, the level of water consumption has been rising day by day, especially with the use of treated water in agricultural (70\%), industrial (80\%) and domestic (22\%) sections, leading to the production of large amounts of wastewater containing innumerable contaminants (1). Color compounds enter the environment from wastewater of various industries such as textile, food, medicine, etc
(2). Dyeing units of textile industry are one of the most important environmental contaminants due to the use of thousands of dyeing chemicals. A significant amount of water is used in this industry and as a result, a large amount of colored wastewater is produced (3). The main characteristics of the wastewater of these industries are high chemical oxygen demand (COD) and existence of various colors. The $\mathrm{BOD} / \mathrm{COD}$ ratio in the wastewater of these industries is about 0.25 , indicates that most compounds in the wastewater of these units are not biodegradable and may also be toxic to living organisms (4). Furthermore, the stability of the molecular structure leads to their resistance against chemical or biological decomposition. Therefore, these compounds, as a vital threat, must be eliminated 
from wastewater before discharge.

In recent years, industries have been under pressure of public opinion and related authorities to treat their wastewater before discharge into the natural environment in an appropriate way. Hence, finding effective treatment methods is necessary and inevitable (5). Adsorption, sedimentation, chemical degradation, optical degradation, filtration, reverse osmosis, coagulation, and chemical oxidation are the most notable techniques used for the elimination of these contaminants (6). It has been recently shown that the adsorption process is an efficient method for removing contaminants from wastewater and the activated carbon is the most frequently used adsorbent. However, the main problem of using this adsorbent is the high cost of its production and the revival of activated carbon. Thus, many studies have been conducted to find cost-effective and more efficient adsorbents to reduce the cost of adsorption in removing the color (7). Clay has been proved to be a low-cost absorbent used in the removal of color from wastewater. Among studied clays, zeolites are recognized as the efficient adsorbents (8). Considering good ion exchange and adsorption capacity as well as high mechanical and thermal stability of natural and synthetic zeolites, they are considered as good alternatives as adsorbent (6). The structure of zeolites is mainly composed of aluminasilicate. Each mole of aluminum is a cation exchange capacity for zeolite structure, so negative ions cannot be exchanged by zeolites (9). Modifying zeolites by a particular surfactant can create a positive charge network in these absorbents to remove anions from aqueous solutions. Cationic surfactants have high affinity for anionic exchange, and can form a highly stable organic coating on the outer surface of the zeolite. This feature of cationic surfactant is used to modify the exterior part of natural zeolites that usually have long-chain alkyl with a quaternary ammonium group like hexadecyl trimethyl ammonium bromide (HDTMA-Br) at the end of their chain (10).

In the adsorption process, several effective parameters namely concentration of adsorbent, favorable adsorption time, temperature, $\mathrm{pH}$ and initial dye concentration of the solution are of great importance. Thermodynamic factors such as enthalpy, entropy, Gibbs free energy and types of adsorption isotherms like Langmuir and Freundlich are examined in the adsorption process (8).

Adsorption is a mass transfer process in which various combinations are in competition to achieve equilibrium (9). In the studies on the adsorption of pollutants on different adsorbents, determining the adsorption isotherm and adsorption capacity are the most important features that should be considered (10). Several isotherm models such as Langmuir and Freundlich can be used for the analysis of experimental data and describing the equilibrium in the adsorbent. These models are used to provide some perspective on the mechanism of adsorption, surface properties, adsorption affinity and to describe the experimental data on adsorption (8). In Langmuir isotherm, it is basically assumed that adsorption occurs in specific homogeneous sites within the adsorbent (11). Adsorbent surface is quite uniform and there are points on the adsorbent surface that have adsorption capacity. Each of these sites is able to adsorb a molecule and there is no interaction between the adsorbed molecules. Therefore, the adsorbed layers have the thickness of a molecule (6). The saturated monolayer isotherm can be represented as:

$\mathrm{q}_{\mathrm{e}}=\mathrm{q}_{\mathrm{m}} \frac{\mathrm{bC}_{\mathrm{e}}}{1+\mathrm{bC}_{\mathrm{e}}}$

The above equation can be rearranged to the following common linear form as equation 2 :

$\frac{\mathrm{C}_{\mathrm{e}}}{\mathrm{q}_{\mathrm{e}}}=\frac{1}{\mathrm{q}_{\mathrm{m}}} \mathrm{C}_{\mathrm{e}}+\frac{1}{\mathrm{bq}_{\mathrm{m}}}$

Where $\mathrm{C}_{e}$ is the equilibrium concentration $(\mathrm{mg} / \mathrm{L}), \mathrm{q}_{\mathrm{e}}$, the amount of the dye molecules adsorbed onto per unit mass of the modified zeolite $(\mathrm{mg} / \mathrm{g}), \mathrm{q}_{\mathrm{m}}$, is $\mathrm{q}_{\mathrm{e}}$ for a complete monolayer $(\mathrm{mg} / \mathrm{g})$, a constant related to the adsorption capacity, and $b$, a constant related to the affinity of the binding sites and energy of adsorption (L/mg) (12).

In Freundlich isotherm, the main assumption is that the adsorbent surface is non-uniform and composed of different levels of adsorption sites. In addition, adsorption on any level of the sites obeys the Langmuir isotherm (7). The Freundlich isotherm is commonly presented as:

$\mathrm{q}_{\mathrm{e}}=\mathrm{k}_{\mathrm{f}} \mathrm{C}_{\mathrm{e}}^{\frac{1}{n}}$

where $k_{f}$ and $n$ are the Freundlich constants associated with the adsorption capacity and adsorption intensity of the sorbent, respectively. Equation 3 can be linearized by taking logarithms (13):

$\ln \mathrm{q}_{\mathrm{e}}=\ln \mathrm{k}_{\mathrm{f}}+\frac{1}{\mathrm{n}} \ln \mathrm{C}_{\mathrm{e}}$

In order to increase the efficiency of the process, a study on adsorption kinetics will be constructive as it provides information about the mechanism of adsorption. In order to apply the adsorption sufficiently, cost-effective, easyto-access and abundant adsorbents with known kinetic parameters and sorption properties are required (13).

The pseudo-first-order model is represented as:

$\mathrm{LnC}-\mathrm{LnC}_{0}=\mathrm{k}_{1} \mathrm{t}$

The pseudo-second-order model is represented as:

$\left(\frac{1}{\mathrm{C}}-\frac{1}{\mathrm{C}_{0}}\right)=-\mathrm{k}_{2} \mathrm{t}$

The intra-particle diffusion model is represented as:

$\mathrm{q}_{\mathrm{t}}=\mathrm{k}_{\mathrm{i}} \mathrm{t}^{1 / 2}$

where $q_{t}$ is the amount of adsorbed adsorbent at time $t$ $\left(\mathrm{mgg}^{-1}\right), \mathrm{k}_{1}$, the pseudo-first-order rate constant $\left(\min ^{-1}\right), \mathrm{k}_{2}$, 
the pseudo-second-order rate constant $\left(\mathrm{gmg}^{-1} \mathrm{~min}^{-1}\right), \mathrm{k}_{\mathrm{i}}$, the intra-particle diffusion rate constant $\left(\mathrm{mgg}^{-1} \mathrm{~min}^{-1 / 2}\right)$ and $\mathrm{t}$, the contact time (min) (14).

Artificial neural networks (ANNs) are now commonly used in many areas of chemistry and they represent a set of methods that may be useful in solving such problems (15-17). One of the characteristics of modeling based on the ANNs is that it does not require the mathematical description of the phenomena involved in the process, and therefore, it might prove usefulness in simulating and upscaling complex adsorption systems.

As the main aim of this study, the removal of anionic dye, direct blue 129 (DB129), from aqueous environment by the modified zeolite and its effective parameters were investigated. Due to the fact that a variety of reactions and interactions occur during the adsorption process, and also for the lack of knowledge about the reactions and complexity of the process, using black box methods such as ANNs would be helpful for modeling. Thus, modeling of the process was carried out using ANN in this research. Another aim of this study was to obtain an ANN model capable of making reliable prediction of the efficiency of the adsorption process.

\section{Materials and Methods}

Direct Blue 129 (DB129), a commercial dye (Boyakhsaz Co., Iran), was selected as the model compound and used without further purification. Molecular structure, molar mass and the maximum absorbance wavelength of the purchased DB129 were $\mathrm{C}_{30} \mathrm{H}_{19} \mathrm{~N}_{5} \mathrm{Na}_{2} \mathrm{O}_{7} \mathrm{~S}_{2}, 671.61 \mathrm{~g} /$ mol and $591 \mathrm{~nm}$, respectively. The chemical structure of the dye is presented in Figure 1a. The surfactant used in this study was hexadecyl trimethyl ammonium bromide (HDTMA-Br) and purchased from Merck (Germany). The chemical structure of the surfactant is shown in Figure $1 \mathrm{~b}$. Zeolite was purchased from Afrazand Co, Tehran, Iran. Hydrochloric acid and sodium hydroxide were used for

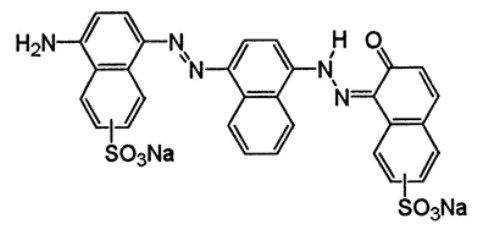

(a)

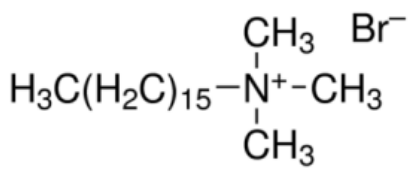

(b)

Figure 1. (a) Chemical structure of direct blue 129, (b) Chemical structure of surfactant.
$\mathrm{pH}$ adjustment and purchased from Merck (Germany). A WTW-720 pH-meter (the Netherlands) was used to measure the solution $\mathrm{pH}$. The samples were stirred using a magnetic stirrer (IKA RHB2, Germany) and the suspensions were centrifuged (CE.148 Shimifan, Iran) for subsequent analysis of the dye concentration. The removal of the dye was followed by SPECORD 250 UV-Vis spectrophotometer (Analytik Jena, Germany). Absorbance was measured at a wavelength of $591 \mathrm{~nm}$. The SEM images were recorded by MIRA3 TESCAN (Brno, Czech) instrument after gold-plating of the samples. FT-IR spectroscopy was performed using a bench-top spectrometer (Bruker Tensor 27, Germany). The X-ray diffraction (XRD) measurements were performed using Siemens X-ray D5000 diffractometer and copper K-alpha $(\mathrm{Cu} \mathrm{Ka})$ radiation at room temperature. The accelerating voltage and emission current were $40 \mathrm{kV}$ and of $30 \mathrm{~mA}$, respectively.

In order to remove impurities, the zeolite was washed several times with distilled water. In order to dry the zeolite particles, they were placed in an oven at $105^{\circ} \mathrm{C}$ for 12 hours. For surface modification of natural zeolite, hexadecyl trimethyl ammonium bromide (HDTMA-Br) was used. So, $10 \mathrm{~g}$ of zeolite was mixed with a solution of $2 \%$ surfactant-zeolite and placed on a magnetic stirrer with speed of $300 \mathrm{rpm}$ for 24 hours. After mixing, zeolites were washed with distilled water, passed through the appropriate filter and dried at $105^{\circ} \mathrm{C}$ for 12 hours (18). The experiments were performed according to Zarei et al (19). $400 \mathrm{~mL}$ graduated cylinder containing $100 \mathrm{~mL}$ dye solution was utilized, in which the adsorbent was added. As in the present study, the samples were taken every 5 minutes, and it had time delay to deposit the adsorbent particles, therefore, the graduated cylinder was utilized for its height. Then, the sampling of dye solution was easier and free from any adsorbent particles. The system was put on a magnetic stirrer at a fixed stirring speed of $300 \mathrm{rpm}$. All the samples were centrifuged to deposit the trifle adsorbent. The speed of centrifuge was fixed on 5000 $\mathrm{rpm}$ for 5 minutes. The desired $\mathrm{pH}$ was adjusted using 0.1 $\mathrm{mol} / \mathrm{L} \mathrm{HCl}$ and $0.1 \mathrm{~mol} / \mathrm{L} \mathrm{NaOH}$ by a $\mathrm{pH}$ meter.

The most important variables affecting the adsorption are $\mathrm{pH}$ of the solution, adsorbent dosage, reaction time, initial dye concentration and temperature. In this study, the effects of these variables on the performance of the prepared adsorbent for the removal of DB129 were investigated. As the concentration of dye in textile wastewaters is $10-100 \mathrm{mg} / \mathrm{L}$, therefore, the removal experiments were performed at different initial dye concentrations (10-100 $\mathrm{mg} / \mathrm{L}), \mathrm{pH}$ values $(2-10)$, adsorbent weights $(0.2-1.2 \mathrm{~g})$ and temperatures $\left(20-70^{\circ} \mathrm{C}\right)$.

The amount of adsorbed dye (q) by the modified zeolite and dye removal efficiency (DR\%) were calculated using Equations 8 and 9, respectively (9).

$\mathrm{q}=\frac{\left(\mathrm{C}_{\mathrm{o}}-\mathrm{C}_{\mathrm{f}}\right) \times \mathrm{V}}{\mathrm{m}}$ 
$D R \%=\frac{\left(\mathrm{C}_{\mathrm{o}}-\mathrm{C}_{\mathrm{f}}\right)}{\mathrm{C}_{\mathrm{o}}} \times 100$

where $\mathrm{q}$ is adsorption capacity in $\mathrm{mg} / \mathrm{g}, \mathrm{C}_{0}$ and $\mathrm{C}_{\mathrm{f}}$ are the initial dye concentrations and post-treatment concentration for a certain period of time $(\mathrm{mg} / \mathrm{L})$, respectively, $\mathrm{V}$ is the volume of each dye solution $(\mathrm{ml})$ and $\mathrm{m}$, the total amount of modified zeolite $(\mathrm{g})$.

Physical properties of the natural zeolite are presented in Table 1. To determine the morphological characteristics of the natural and modified zeolites, their SEM images were obtained. As shown in Figure 2a and b, the surface of modified zeolite is flatter and more uniform than the initial zeolite. The modified zeolite was analyzed by XRD to determine the structure with comparison to clinoptilolite reference. XRD analysis of zeolite indicated that the type of zeolite was clinoptilolite (Figure 2c). To analyze surface properties of both modified and unmodified zeolites, FT-IR spectra were used. FT-IR image shows that the most significant factor groups with the highest frequency of the absorption include hydroxyl (O-H) groups with peak of $3622.61 \mathrm{~cm}^{-1}$, which form hydrogen bonds between water molecules (Figure 2d). Two peaks at wave numbers of $3448.78 \mathrm{~cm}^{-1}$ and 1626.84 $\mathrm{cm}^{-1}$ show stretching and bending strength of the O-H groups in zeolites, respectively. Existence of three peaks at wave numbers of 1061.76, 795.79 and $607.14 \mathrm{~cm}^{-1}$, represents the stretching vibration of the $\mathrm{Si}-\mathrm{O}$ bonds in zeolite structure. The peak appeared at wave number of $467.66 \mathrm{~cm}^{-1}$ is due to stretching vibration of Al-O-Si bond. Two peaks appeared at wave numbers of 2926.54 and $2855.19 \mathrm{~cm}^{-1}$ after modification, are probably related to the surfactant chains (Figure 2a). There is also a peak in the wave number of $1633.34 \mathrm{~cm}^{-1}$ related to the vibrations of the $\mathrm{NH}$ group bonds which could be due to the nitrogen atoms of surfactant molecules, demonstrating successful operation of the modification on zeolite (20). To determine the charge of adsorbent surface, $\mathrm{pH}_{z \mathrm{zc}}$ (zero point of charge) test was used. Solid addition method (21) was used to determine the point of zero charge of the adsorbent.

Table 1. Chemical composition of the natural zeolite

\begin{tabular}{lc}
\hline Constituent & Zeolite (\%wt) \\
\hline $\mathrm{SiO}_{2}$ & 67.44 \\
$\mathrm{Al}_{2} \mathrm{O}_{3}$ & 10.90 \\
$\mathrm{Fe}_{2} \mathrm{O}_{3}$ & 0.84 \\
$\mathrm{TiO}_{2}$ & 0.19 \\
$\mathrm{CaO}$ & 1.24 \\
$\mathrm{MgO}$ & 0.33 \\
$\mathrm{Na}_{2} \mathrm{O}$ & 3.71 \\
$\mathrm{~K}_{2} \mathrm{O}$ & 4.39 \\
$\mathrm{~S}$ & 0.47 \\
Loss on ignition & 11.05 \\
\hline
\end{tabular}
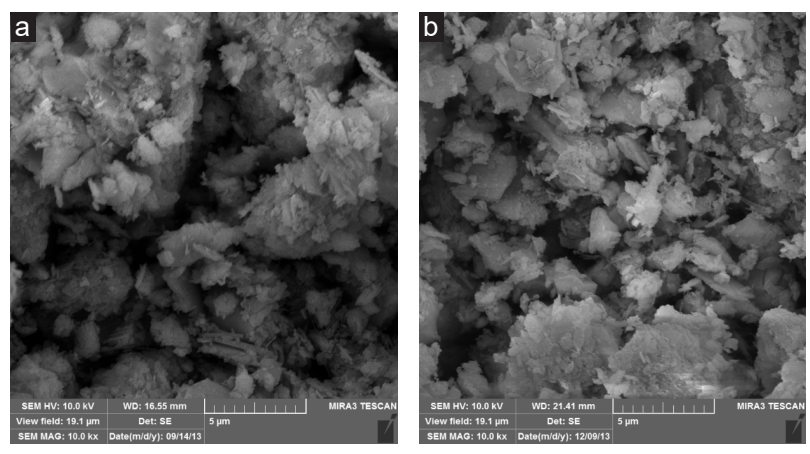

(c)
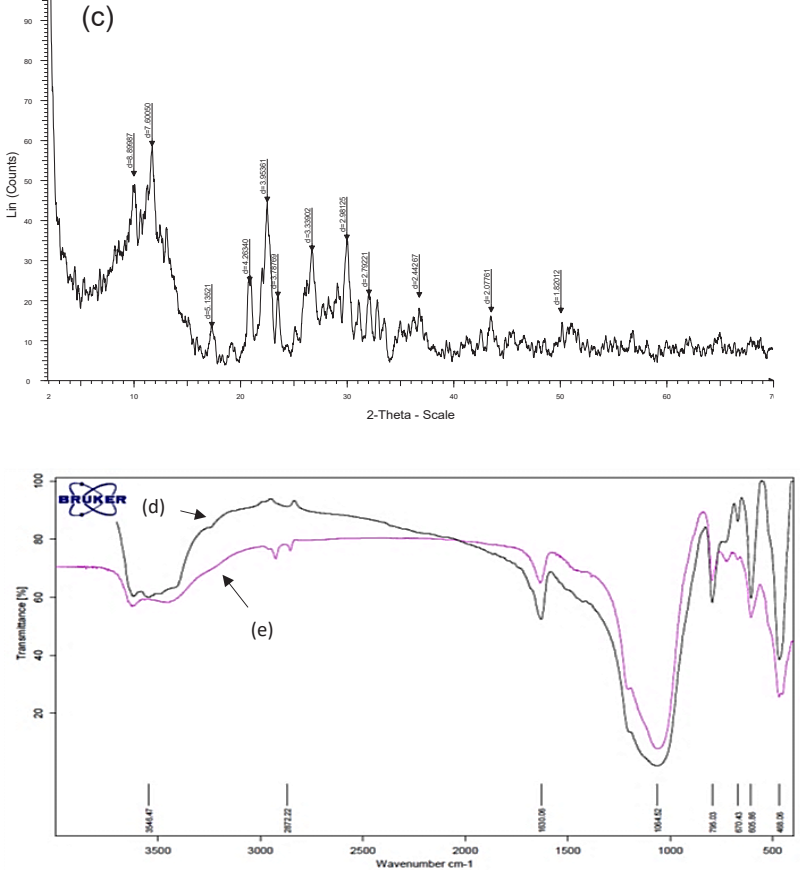

Figure 2. SEM images of (a) natural zeolite and (b) modified zeolite, (c) X-ray diffractogram of the natural zeolite, FT-IR spectrum of (d) natural zeolite and (e) modified zeolite.

Erlenmeyer flasks containing dye solution $(100 \mathrm{mg} / \mathrm{L})$ and modified zeolite $(0.3 \mathrm{~g})$ were used to carry out the adsorption kinetic experiments. The magnetically stirring of the flasks was done at $300 \mathrm{rpm}$ and constant temperature $20^{\circ} \mathrm{C}$. The samples were taken at predetermined time intervals, centrifuged and analyzed to determine the residual dye concentrations.

MATLAB 7 mathematical software equipped with ANN toolbox was used to carry out all ANN calculations. First, data were preprocessed before training the ANN. The following steps were performed in preprocessing: eliminating correlated input variables, transformation, scaling and biasing. In this study, a three-layer network with a sigmoidal transfer function (trainscg) and back propagation algorithm was designed. The trainscg function does not require line search at each iteration step like other conjugate training functions. Step size scaling mechanism which avoids a time consuming line search per learning iteration, was used in this study. This mechanism makes the algorithm faster than any other 
second order algorithms. The trainscg function requires more iteration to converge than the other conjugate gradient algorithms, but the number of computations in each iteration was significantly reduced because no linear search was performed (22).

\section{Results}

Determination of the optimum surfactant-zeolite ratio (\%) Modification of zeolite by the surfactant depends on the surfactant adsorption degree on the zeolite. In order to adsorb anions on the modified zeolite, the modified surface should have positively-charged exchange sites. These sites are formed when double layers of the surfactant were completely formed on the zeolite. It has been shown that to form a double layer surfactant, the HDTMA-Br ratio of adsorbent to external cation exchange capacity (ECEC) of zeolites should be 2:1 (18). Figure 3 shows the dye removal efficiency of DB129 using different ratios (\%) of surfactant-Zeolite. As shown in this figure, in the ratio of 2 to $4 \%$, the adsorption potential was increased due to the formation of double layer surfactants on the surface of the zeolite. To save the expense, a $2 \%$ solution of surfactant-zeolite was used.

Effects of operational parameters on the removal efficiency of DB129

Effect of adsorbent dosage and reaction time

The effect of the modified zeolite amount on the removal of DB129 was studied. Different amounts of adsorbent (0.2-1.2 g) were added to a volume of $100 \mathrm{~mL}$ of the dye solution with initial concentration of $50 \mathrm{mg} / \mathrm{L}$ at room temperature. After equilibration (90 minutes), the samples were centrifuged and the dye concentration in the solution was measured. Results are shown in Figure 4a. As shown in this figure, by increasing the adsorbent dosage from 0.2 to $1.2 \mathrm{~g}$, dye removal efficiency was significantly increased. On the other hand, Figure 4a shows that the dye removal efficiency increased rapidly up to $0.3 \mathrm{~g}$ of the adsorbent and then its slope decreased. So, the adsorbent dosage of $0.3 \mathrm{~g}$ was used for the next experiments from an

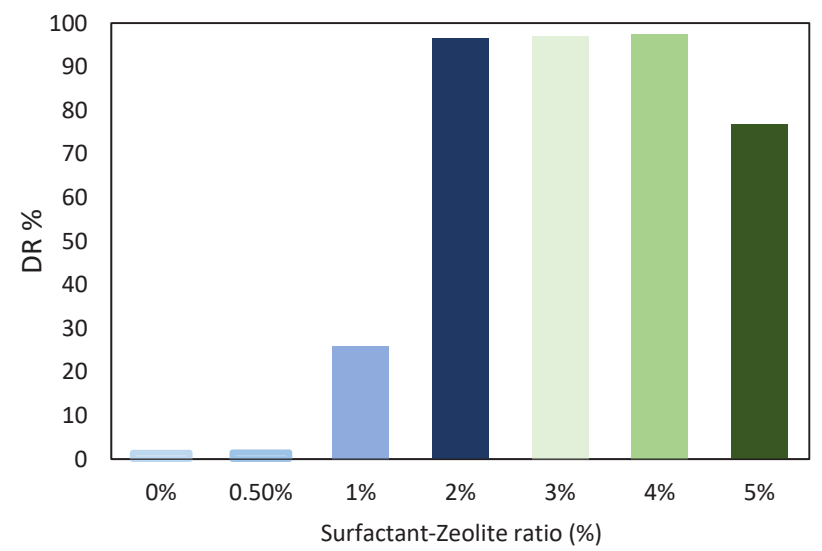

Figure 3. The dye removal efficiency of DB129 using different surfactant-zeolite ratios (\%). economic perspective.

One of the most important variables in the adsorption process is reaction time. Adsorption capacity and removal efficiency of the dye by the adsorbent had a direct relationship with reaction time. According to Figure 4a, as time passed, the adsorption capacity increased and reached a constant value at a specified time, after which no dye molecule could be removed from the solution (23).

\section{Effect of $\mathrm{pH}$}

The solution $\mathrm{pH}$ also plays an effective role in the whole process and absorbing capacity. It affects the surface charge of the adsorbent and the degree of ionization and specification of the adsorbate (24). Many researchers believe that $\mathrm{pH}$ is of great importance in electrostatic attraction between the adsorbent and dye (14). For a closer look at the process of adsorption, the impact of $\mathrm{pH}$ on the removal efficiency of the dye was investigated. Figure $4 \mathrm{~b}$ shows dye removal efficiency (DR\%) of DB129 by the modified zeolite at different $\mathrm{pH}$ values as a function of time. The results indicate that the adsorption increased as the $\mathrm{pH}$ value was around acidic $\mathrm{pHs}$. The adsorption mechanism can be easily evaluated by determining the point of zero charge on adsorbent surface $(25,26)$. The $\mathrm{pH}$ $>\mathrm{pH}_{\mathrm{zpc}}$ helps increase the adsorption of cations while the

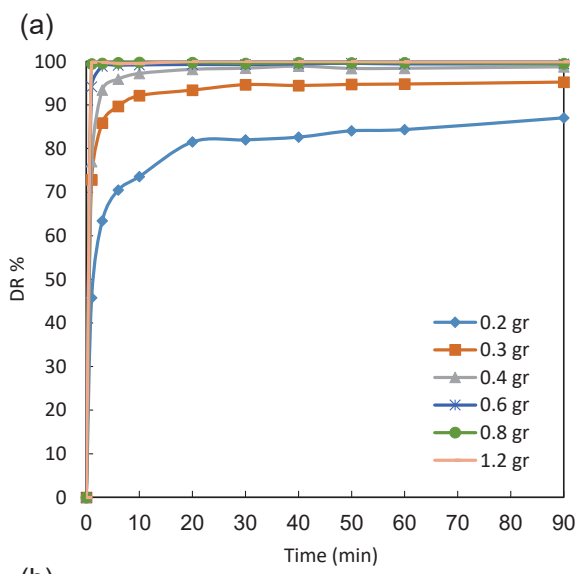

(b)

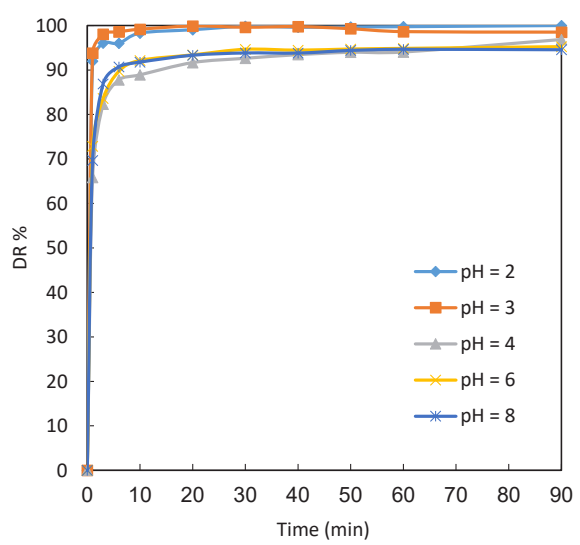

Figure 4. (a) Effect of different dosages of adsorbent on adsorption of DB129 ( $\mathrm{pH}=7$, [DB129]o=50 mg/L), (b) Effect of $\mathrm{pH}$ on adsorption of DB129 (adsorbent weight $\left.=0.3 \mathrm{~g},[\mathrm{DB} 129]_{\circ}=50 \mathrm{mg} / \mathrm{L}\right)$. 
$\mathrm{pH}<\mathrm{pH}_{\mathrm{zpc}}$ helps enhance the adsorption of anions. The results show that the $\mathrm{pH}_{\mathrm{zpc}}$ for the adsorbent was 7 (Figure 5). This means that the charge of adsorbent surface in $\mathrm{pH}=$ 7 was zero or neutral. The results also showed that there was no significant variation in the $\mathrm{pH}$ range of 4 to 8 . On the other hand, the structure of the pollutant (DB129) can be affected by the acidic environment. So, pH 7 (neutral $\mathrm{pH}$ of the dye and adsorbent) was chosen as the optimum $\mathrm{pH}$.

\section{Effect of initial dye concentration and temperature}

The initial concentration of the dye is another important operational factor. Therefore, the removal of DB129 was investigated in the dye concentrations of $20-100 \mathrm{mg} / \mathrm{L}$ under optimum conditions of $0.3 \mathrm{~g}$ adsorbent and $\mathrm{pH} 7$. According to Figure 6a, with increasing concentrations of the dye from 20 to $100 \mathrm{mg} / \mathrm{L}$, dye removal efficiencies was reduced from about $100 \%$ to $79 \%$ in a reaction time of 90 minutes.

For a closer look at the process of adsorption, the influence of temperature on the efficiency of adsorption was examined (Figure 6b). As shown in this figure, the percentage of dye removal was increased by increasing temperature.

\section{Effect of stirrer's speed}

Solutions with an initial dye concentration of $50 \mathrm{mg} / \mathrm{L}$ and other optimum conditions were prepared and stirred at $300 \mathrm{rpm}, 900 \mathrm{rpm}$, and $1200 \mathrm{rpm}$ under the influence of the adsorbent. The results are shown in the Figure 7. As can be seen in this figure, the stirrer speed had no significant impact on the adsorption rate.

\section{Adsorption isotherms}

In order to establish the most appropriate correlations for the equilibrium data in the design of adsorption system for adsorption of DB129 onto the modified zeolite, two common isotherm models were tested: Langmuir and Freundlich models. The applicability of the isotherm

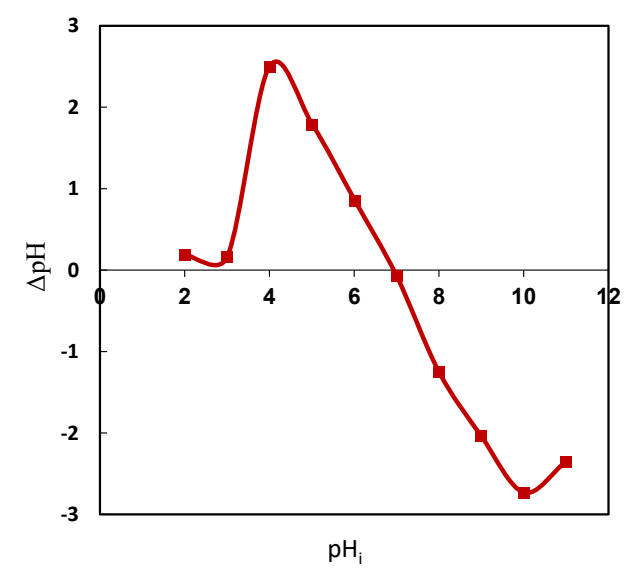

Figure 5. Determination of $\mathrm{pH}$ of zero point of charge $\left(\mathrm{pH}_{\mathrm{ZPC}}\right)$ of the adsorbent.
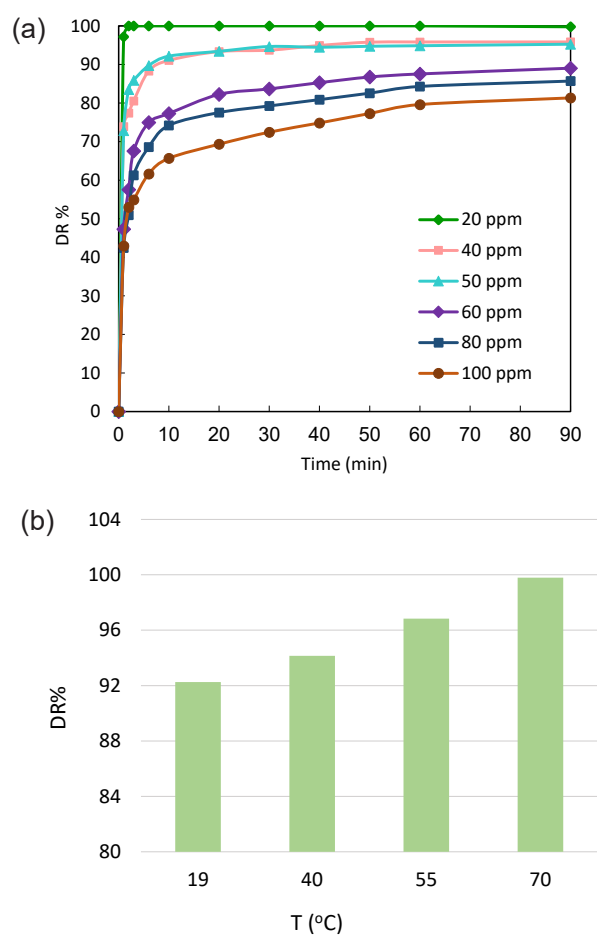

Figure 6. (a) Effect of the initial concentration of DB129 on the removal efficiency $(\mathrm{pH}=7$, adsorbent weight $=0.3 \mathrm{~g})$, (b) Effect of temperature on the removal efficiency of DB129 $(\mathrm{pH}=7$, adsorbent weight $=0.3 \mathrm{~g}$, $[\mathrm{DB} 129]_{0}=50 \mathrm{mg} / \mathrm{L}$, reaction time $\left.=90\right)$.

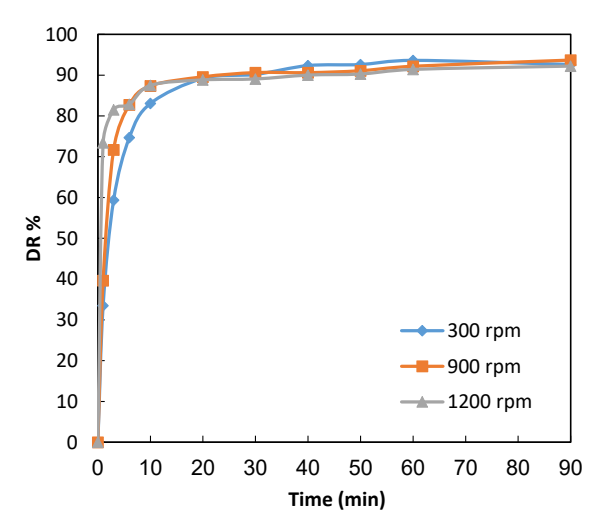

Figure 7. Effect of stirrer's speed on the removal efficiency of DB129 (adsorbent weight $=0.3 \mathrm{~g}, \mathrm{pH}=7,[\mathrm{DB} 129]_{0}=50 \mathrm{mg} / \mathrm{L}$ )..

equations was compared by judging the correlation coefficients $\left(\mathrm{R}^{2}\right)$. For the Langmuir isotherm model (equation 2), a linear plot is obtained when $\mathrm{C}_{e} / \mathrm{q}_{\mathrm{e}}$ is plotted against $\mathrm{C}_{\mathrm{e}}$ over the entire concentration range of DB129 (Figure 8a). The Langmuir model effectively and significantly described the adsorption data with $\mathrm{R}^{2}$ values $\geq 0.98$. For the Freundlich isotherm model (equation 4), plotting $\ln _{e}$ against $\ln C_{e}$ over the entire concentration range of investigated dye concentrations leads to a linear plot (Figure $8 \mathrm{~b}$ ). The plot between $\mathrm{Lnq}_{\mathrm{e}}$ and $\mathrm{LnC}_{\mathrm{e}}$ yielded a straight line with $\mathrm{R}^{2}=0.875$. The calculated constants of the isotherms are presented in Table 2. As shown in this table, the $\mathrm{R}^{2}$ values suggest that the Langmuir isotherm 
(a)

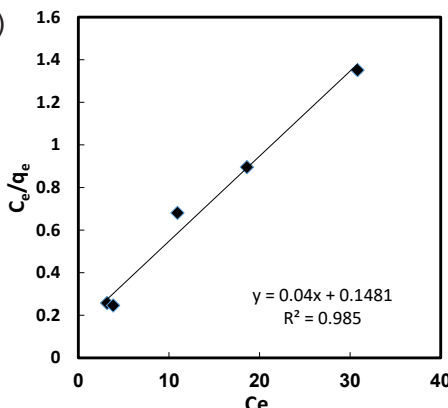

(b)

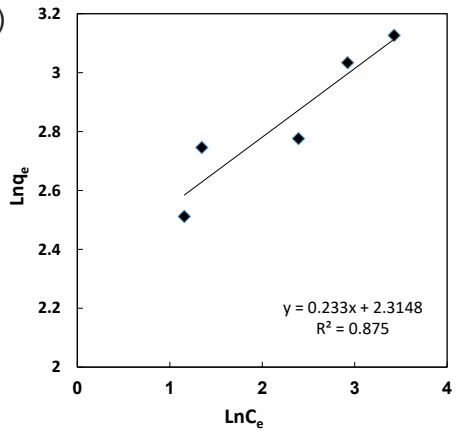

Figure 8. (a) Fit of Langmuir isotherm, (b) Freundlich isotherm data for the adsorption of DB129 onto the modified zeolite.

Table 2. Isotherm constants and correlation coefficients for adsorption of DB129 onto the modified zeolite

\begin{tabular}{ccc}
\hline Model & Parameter & Amount \\
\hline \multirow{2}{*}{ Langmuir } & $\mathrm{q}_{\mathrm{m}}$ & 25 \\
& $\mathrm{~B}$ & 0.27 \\
& $\mathrm{R}^{2}$ & 0.985 \\
\hline \multirow{2}{*}{ Freundlich } & $\mathrm{K}_{\mathrm{f}}$ & 10.12 \\
& $\mathrm{~N}$ & 4.29 \\
& $\mathrm{R}^{2}$ & 0.875 \\
\hline
\end{tabular}

provided a good fit to the isotherm data.

Adsorption kinetics

To analyze the kinetic data, pseudo-first-order (Figure 9a), pseudo-second-order (Figure 9b) and intra particle diffusion (Figure 9c) models were used and the obtained $\mathrm{R}^{2}$ values were $0.587,0.957$ and 0.613 , respectively. It can be noticed that the equilibrium adsorption obtained from the pseudo-second-order model was close to the experimental data, suggesting better application of the second-order kinetics. This confirms that the sorption data were well represented by the pseudo-second-order kinetics for the entire sorption period. For the diffusion model plots, a 2-phase process can be observed, showing that the adsorption process proceeded by surface sorption and intraparticle diffusion. The initial curved portion of the plot indicates a boundary-layer effect while the second linear portion is due to intraparticle or pore diffusion (14).

Analyzing thermodynamic parameters of the adsorption process
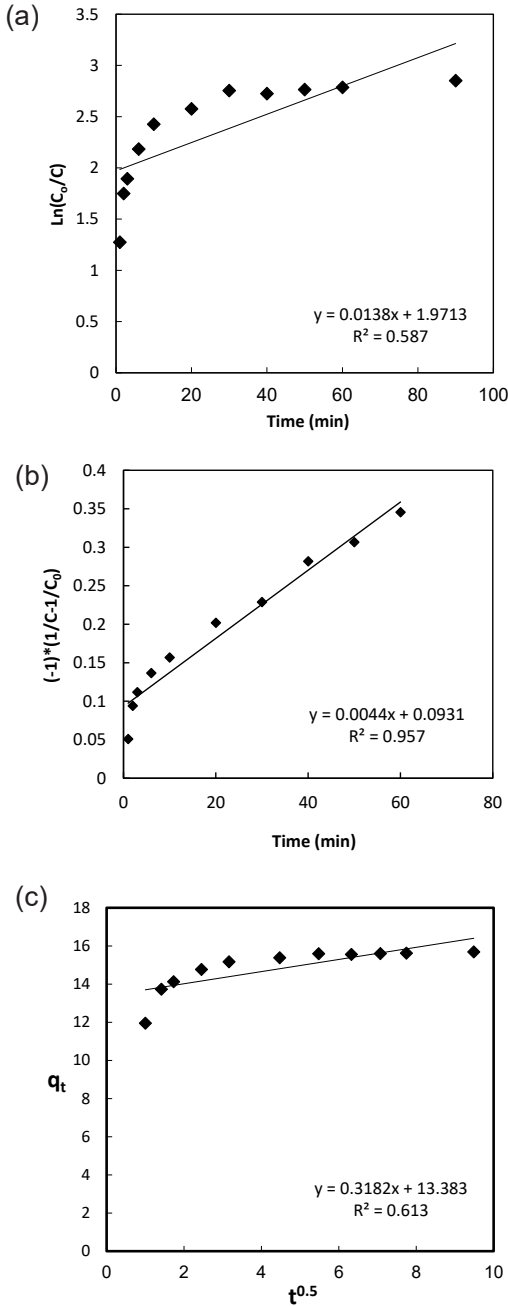

Figure 9. (a) Pseudo-first-order, (b) Pseudo-second-order and (c) Diffusion model kinetics for adsorption of DB129 on modified zeolite.

Thermodynamics is a study field covering energy changes associated with the physical and chemical changes. A great deal of useful information about some thermodynamic parameters such as enthalpy, entropy and Gibbs free energy can be achieved through temperature dependence of the adsorption process (27).

Considering the adsorption equilibrium constant $\mathrm{k}_{\mathrm{L}}$ in the Langmuir isotherm, thermodynamic parameters, i.e., free energy $\left(\Delta \mathrm{G}^{\circ}\right)$, enthalpy $\left(\Delta \mathrm{H}^{\circ}\right)$ and entropy $\left(\Delta \mathrm{S}^{\circ}\right)$ changes were also calculated via Equations 10-12 (28). The results are presented in Table 3.

$$
\begin{aligned}
\Delta \mathrm{G}^{\circ} & =-\mathrm{RT} \ln \mathrm{K}_{\mathrm{L}} \\
\Delta \mathrm{H}^{\circ} & =-\mathrm{R}\left(\frac{\mathrm{T}_{2} \mathrm{~T}_{1}}{\mathrm{~T}_{2}-\mathrm{T}_{1}}\right) \ln \frac{\mathrm{K}_{\mathrm{L} 1}}{\mathrm{~K}_{\mathrm{L} 2}} \\
\Delta \mathrm{S}^{\circ} & =\frac{\Delta \mathrm{H}^{\circ}-\Delta \mathrm{G}^{\circ}}{\mathrm{T}}
\end{aligned}
$$

where $\mathrm{K}_{\mathrm{L} 1}$ and $\mathrm{K}_{\mathrm{L} 2}$ are the Langmuir constants at $\mathrm{T}_{1}=20^{\circ} \mathrm{C}$ and $\mathrm{T}_{2}=45^{\circ} \mathrm{C}$. 
Table 3. Thermodynamic parameters for adsorption of DB129 onto the modified zeolite

\begin{tabular}{|c|c|c|c|c|c|}
\hline$\Delta \mathrm{S}^{\circ}(\mathrm{J} / \mathrm{molK})$ & $\Delta \mathrm{H}^{\circ}(\mathrm{kJ} / \mathrm{mol})$ & $\left(\Delta \mathrm{G}^{\circ}\right)(\mathrm{kJ} / \mathrm{mol})$ & $\operatorname{Ln} K_{L}$ & $\mathrm{~K}(\mathrm{~L} / \mathrm{mol})$ & $\mathrm{T}\left({ }^{\circ} \mathrm{C}\right)$ \\
\hline \multirow{2}{*}{0.241} & \multirow{2}{*}{41.181} & -29.410 & 12.108 & 181350.9 & 20 \\
\hline & & -35.209 & 13.395 & 656893.2 & 45 \\
\hline
\end{tabular}

As shown in Table 3, the Gibbs free energy change $(\Delta \mathrm{G})$ was negative, and the adsorption enthalpy $(\Delta \mathrm{H})$ and the adsorption entropy $(\Delta \mathrm{S})$ changes were greater than zero.

Neural network modeling

ANNs are directly inspired from the biology of human brain, in which the interconnection among billions of neurons leading to processing a variety of complex information. Similarly, a computational neural network includes simple processing units called neurons. Generally, as shown in Figure 10a, a neural net is parallel interconnected structure consisting of: (1) input layer of neuron (independent variables), (2) a number of hidden layers and (3) output layer (dependent variables). The nature of the problems determines the number of input and output neurons. Hidden layers act as feature detectors and theoretically, there are probably more than a single hidden layer. However, based on the universal approximation theory, a network with a single hidden layer and a sufficiently large number of neurons can interpret any input-output structure (29).

To determine the topology of an ANN, the number of both its layers and nodes in each layer as well as the nature of transfer functions are key factors. In developing the model, optimization of ANN topology is probably the main determining step. In this study, a three-layer feed forward back propagation neural network (5:12:1) was used for modeling the adsorption process (Figure 10a). The input variables for the feed forward neural network were as follows: contact time ( $\mathrm{min}$ ), adsorbent dosage $(\mathrm{g})$, initial $\mathrm{pH}$, initial dye concentration $(\mathrm{mg} / \mathrm{L})$ and temperature $\left({ }^{\circ} \mathrm{C}\right)$. Dye removal efficiency (DR\%) was chosen as the experimental response or output variable. In order to determine the optimum number of hidden nodes, a series of topologies, in which the number of nodes were varied from 2 to 20 , was used.

To prevent the risk of random correlation resulted from random initialization of the weights, each topology was repeated three times. The mean square error (MSE) was used as the error function. MSE measures the performance of network according to the following equation:

$$
\operatorname{MSE}=\frac{1}{\mathrm{Q}} \sum_{\mathrm{i}=1}^{\mathrm{i}=\mathrm{Q}}\left(\mathrm{y}_{\mathrm{i}, \text { pred }}-\mathrm{y}_{\mathrm{i}, \exp }\right)
$$

where $Q$ is the number of data point, $y_{i, \text { pred }}$, network prediction, $\mathrm{y}_{\mathrm{i}, \text { exp }}$, experimental response and $\mathrm{i}$, an index of data. The relation between network error and the number of neurons in the hidden layer is illustrated in Figure 10b. As shown in this figure, the mean square error was minimum when the number of neurons equaled to 12 . In this study, the tan-sigmoid transfer function was used as a transfer function in the hidden layer. This is the most widely used transfer function, which is given by:

$f(x)=\frac{1}{1+\exp (-x)}$

where $f(x)$ represents hidden neuron output (30). The

(a)

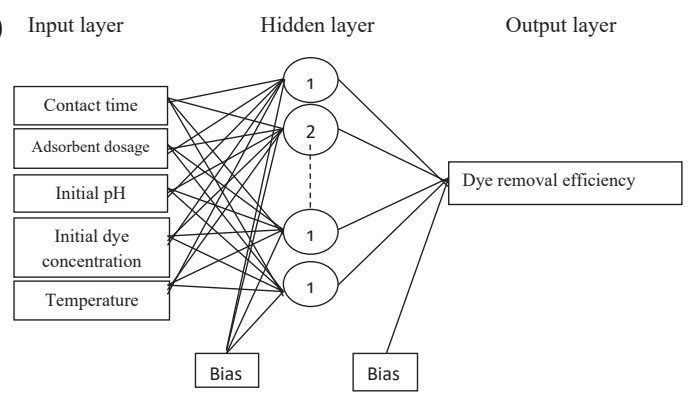

(b)

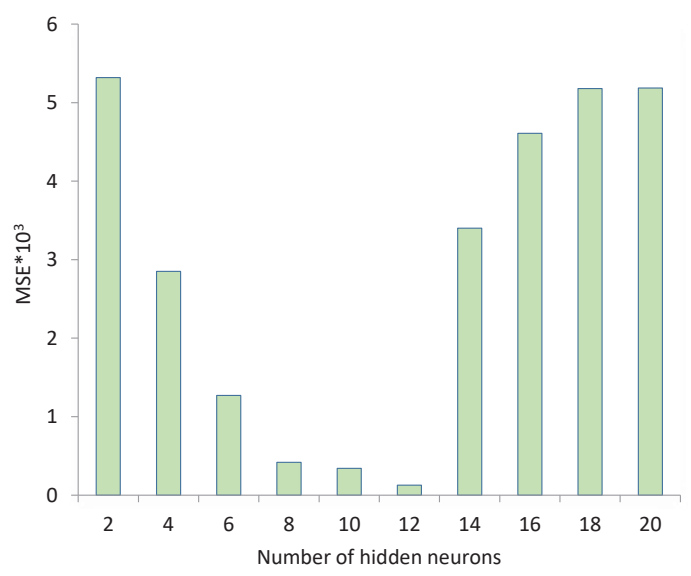

(c)

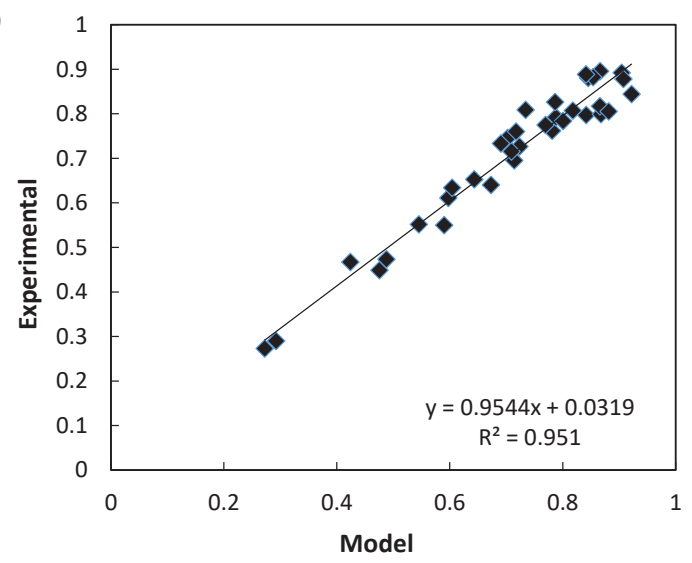

Figure 10. (a) The ANN optimized structure, (b) Effect of the number of neurons in hidden layer on the performance of the neural network, (c) Comparison of the experimental results with those calculated via neural network modeling for the test sets. 
training function was trainscg. After generating several data points, 173 experimental sets were used to feed the ANN structure. Table 4 summarizes the range of studied variables. The samples were divided into three subsets: training, validation and test, each contains 104, 34 and 35 samples, respectively. In order to evaluate the validation and modeling power of the model, the validation and test sets were randomly selected from the experimental data. Considering sigmoid transfer function used in the hidden layer, all samples should be scaled from 0.1 to 0.9 . So any samples $\left(\mathrm{X}_{\mathrm{i}}\right)$ (from the training, validation and test sets) were scaled to a new value $\left(\mathrm{A}_{\mathrm{i}}\right)$ as follows:

$$
\mathrm{A}_{\mathrm{i}}=0.8\left[\frac{\mathrm{X}_{\mathrm{i}}-\min \left(\mathrm{X}_{\mathrm{i}}\right)}{\max \left(\mathrm{X}_{\mathrm{i}}\right)-\min \left(\mathrm{X}_{\mathrm{i}}\right)}\right]+0.1
$$

where $\min \left(\mathrm{X}_{\mathrm{i}}\right)$ and $\max \left(\mathrm{X}_{\mathrm{i}}\right)$ are two extreme values of variable $X_{i}(31)$. To calculate training, validation and test errors, an inverse range scaling was performed on all outputs to return the predicted responses to their original scale, and then a comparison between them and experimental responses was performed. The weights

Table 4. Model variables and their ranges

\begin{tabular}{cl}
\hline Range & Variable \\
\hline $0-90$ & $\begin{array}{l}\text { Input layer } \\
\text { Contact time }(\mathrm{min})\end{array}$ \\
$0.2-1.2$ & Adsorbent dosage $(\mathrm{g})$ \\
$2-10$ & Initial $\mathrm{pH}$ \\
$20-100$ & Initial dye concentration $(\mathrm{mg} / \mathrm{L})$ \\
$20-70$ & Temperature $\left({ }^{\circ} \mathrm{C}\right)$ \\
$0-100$ & $\begin{array}{l}\text { Output layer } \\
\text { Dye removal efficiency }(\mathrm{DR} \%)\end{array}$ \\
\hline
\end{tabular}

listed in Table 5 were provided by the ANN used in this study. The weights are coefficients between the artificial neurons, analogous to synapse strengths between the axons and dendrites in real biological neurons.

Thus, the proportion of the incoming signal transmitted into the neuron's body will be decided by each weight (32). Using neural network model, the calculated and experimental values of the output variable for test sets were compared, the results are shown in Figure 10c. The plot in this figure has correlation coefficient of 0.951 for test set. In order to assess the relative importance of the various input variables on the output variables, the neural net weight matrix can be used. The following equation was proposed based on the partitioning of connection weights (17):

$$
\mathrm{I}_{\mathrm{j}}=\frac{\sum_{\mathrm{m}=1}^{\mathrm{m}=\mathrm{N}_{\mathrm{h}}}\left(\left(\left|\mathrm{w}_{\mathrm{jm}}^{\mathrm{ih}}\right| / \sum_{\mathrm{k}=1}^{\mathrm{N}_{\mathrm{i}}}\left|\mathrm{w}_{\mathrm{km}}^{\mathrm{ih}}\right|\right) \times\left|\mathrm{w}_{\mathrm{mn}}^{\mathrm{ho}}\right|\right)}{\sum_{\mathrm{k}=1}^{\mathrm{k}=\mathrm{N}_{\mathrm{i}}}\left\{\sum_{\mathrm{m}=1}^{\mathrm{m}=\mathrm{N}_{\mathrm{h}}}\left(\left|\mathrm{w}_{\mathrm{km}}^{\mathrm{ih}}\right| / \sum_{\mathrm{k}=1}^{\mathrm{N}_{\mathrm{i}}}\left|\mathrm{w}_{\mathrm{km}}^{\mathrm{ih}}\right|\right) \times\left|\mathrm{w}_{\mathrm{mn}}^{\mathrm{ho}}\right|\right\}}
$$

where $I_{j}$ represents the relative importance of the jth input variable on the output variable, $\mathrm{N}_{\mathrm{i}}$ and $\mathrm{N}_{\mathrm{h}}$ are the numbers of input and hidden neurons, respectively, Ws are connection weights, the superscripts 'i', ' $h$ ' and 'o' refer to input, hidden and output layers, respectively, and subscripts ' $k$ ', ' $m$ ' and 'n' refer to input, hidden and output neurons, respectively. Equation 16 was used to calculate the relative importance of input variables on the value of dye removal efficiency, the results are shown in Table 6 . Apparently, all of the variables have strong impacts on the dye removal efficiency. Therefore, it could make a lot of problems if we had neglected any of the variables studied in this work in the present analysis.

Discussion

\begin{tabular}{|c|c|c|c|c|c|c|c|c|}
\hline$W_{1}$ & & & & & & & \multicolumn{2}{|l|}{$w_{2}$} \\
\hline \multirow[t]{2}{*}{ Neuron } & \multicolumn{5}{|c|}{ Variable } & \multirow[t]{2}{*}{ Bias } & Neuron & Weight \\
\hline & Contact Time & Initial pH & Temperature & Adsorbent dosage & Initial dye concentration & & & \\
\hline 1 & $1.5153-$ & -1.206 & -1.0765 & -0.98781 & 0.597 & 2.387 & 1 & 0.289 \\
\hline 2 & 0.31619 & -1.1808 & -1.0227 & -0.790 & -1.161 & 2.283 & 2 & -1.997 \\
\hline 3 & 0.17527 & -1.209 & -0.14767 & 0.689 & -0.617 & -0.958 & 3 & 1.293 \\
\hline 4 & 0.03132 & -1.987 & 0.42872 & -4.847 & -1.395 & -1.596 & 4 & 2.206 \\
\hline 5 & $0.0150-$ & -0.9571 & -0.24554 & -0.839 & -0.174 & -0.064 & 5 & -1.912 \\
\hline 6 & -5.9990 & 0.22319 & 2.9106 & 0.045 & 2.185 & -0.904 & 6 & 2.256 \\
\hline 7 & 4.8948 & 0.48685 & -2.7133 & -2.562 & 0.301 & 0.509 & 7 & 2.464 \\
\hline 8 & 2.9179 & 3.3064 & -0.68747 & -0.830 & -3.911 & 1.149 & 8 & -2.593 \\
\hline 9 & 1.1536- & -0.04699 & 1.4854 & 0.941 & 1.954 & -1.507 & 9 & 2.382 \\
\hline 10 & 0.6060 & -0.72282 & 1.1852 & -3.462 & 0.557 & 1.054 & 10 & -2.507 \\
\hline 11 & 7.3751- & -2.4904 & 1.0426 & 1.484 & 0.229 & -7.661 & 11 & -5.949 \\
\hline \multirow[t]{2}{*}{12} & -0.0573 & 0.38485 & -1.7442 & -1.699 & 2.240 & -5.204 & 12 & -5.020 \\
\hline & & & & & & & Bias & -1.170 \\
\hline
\end{tabular}

Table 5. Matrix of weights

W1: weights between input and hidden layers; W2: weights between hidden and output layers. 
Table 6. Relative importance of input variables on the value of decoloration efficiency

\begin{tabular}{lc}
\hline Variable & Importance \\
\hline Contact time $(\mathrm{min})$ & 27.18 \\
Adsorbent dosage $(\mathrm{g})$ & 22.64 \\
Initial dye concentration $(\mathrm{mg} / \mathrm{L})$ & 17.06 \\
Initial pH & 16.88 \\
Temperature $\left({ }^{\circ} \mathrm{C}\right)$ & 16.24 \\
\hline Total & 100 \\
\hline
\end{tabular}

According to Figure 4a, by increasing the amount of the adsorbent dye removal efficiency was considerably increased, due to the greater surface area and more adsorption sites (18). Since a certain volume of liquid was treated by each particle of adsorbent, increasing the amount of adsorbent accelerated the equilibrium between the adsorbent and adsorbed. It is also related to the effect of flow splitting (concentration gradient between the adsorbent and adsorbed). It means that in the higher concentration of the adsorbent, a very rapid adsorption occurs on the surface of the adsorbent, which reduces the concentration of solute in solution compared to the condition where lower concentration of adsorbent is used (33). In general, anionic dyes due to the hydrophobic interactions can be absorbed on the zeolite surface. In addition, applying a modification process by cationic surfactant and placing its molecules on the zeolite surface can led to a number of positive sites $\left(\mathrm{R}-\mathrm{N}^{+}\right)$that can be added on the surface of the zeolite. Because of the electrostatic interaction, the adsorption capacity is increased (34). Figure $4 \mathrm{a}$ also shows the time dependence of the dye adsorption onto modified zeolite. The adsorption capacity increased with reaction time and reached an equilibrium state within a specified time. Previous studies also have supported the present findings that a fixed quantity of adsorbent could only offer a finite number of surface binding sites, some of which would be saturated by competing dye molecules, especially at relatively high dye concentrations (35).

As shown in Figure 4b, the removal efficiency was increased in acidic $\mathrm{pH}$ conditions due to creating a positive surface charge (24). The results of Figure 5 also confirm this finding and show that the $\mathrm{pH}_{\mathrm{zpc}}$ for the adsorbent was 7 . At $\mathrm{pH}$ below 7, adsorbent charges were positive and at $\mathrm{pH}$ above 7 , adsorbent charges were negative. As the dye used in this study was an anionic dye, the percentage of anionic dye removal from the solution increased at low $\mathrm{pH}$ values due to the electrostatic attraction between the positive surface charge of the adsorbent and anionic dye. A similar observation was reported for adsorption of solar red and brittle blue direct dyes onto Eucalyptus angophoroides bark (36) and crystal violet onto biopolymers composites (37). According to Figure $6 \mathrm{a}$, with increasing the dye concentrations, dye removal efficiencies was reduced.
The reason for this behavior is that with increasing the dye concentration, repulsion is created between the dye molecules and they cannot be adsorbed by the adsorbent. The existence of sufficient available adsorption sites at low concentrations is the main reason for the high adsorption efficiency (10). This can be due to the fact that there are only limited parts on the adsorbent surface to adsorb the dye, and as the concentration of the dye is increasing, the chance of dye molecules for being adsorbed will be decreased (31).

It can be seen that the adsorption capacity of the dye increased with increasing the temperature (Figure 6b). Increasing temperature leads to an increase in the diffusion rate of adsorbed molecules through the boundary layer and the internal cavities of the adsorbent particles, so the percentage of dye removal is increased. Moreover, the change in temperature will be reflected in the change of the equilibrium capacity of adsorption (38). The physical adsorption is an exothermic process, and the adsorption capacity of the adsorbate always decreases with increasing the temperature. It is apparent that the adsorption of DB129 molecules on the modified zeolite is an endothermic process implying a chemical adsorption process (39). Other researchers have reported a similar observation for adsorption of heavy metal ions onto poly(amidoxime) $/ \mathrm{SiO}_{2}$ (38) and amidoxime-type adsorbents (40).

The experimental adsorption isotherms according to the initial and equilibrium dye concentration have been performed (Figures $8 \mathrm{a}, 8 \mathrm{~b}$ and Table 2). The equilibrium data were best represented by the Langmuir isotherm model. The Langmuir adsorption isotherm describes the homogeneous surface assuming that all the adsorption surface sites have identical adsorbate affinity and that adsorption at one site does not affect an adjacent site. Furthermore, each adsorbate molecule was located on a single site and hence it can be considered as the monolayer formation of an adsorbate onto the adsorbent surface (41). According to the assumption of the Langmuir isotherm model, the adsorption of DB129 onto modified zeolite occurred as a monolayer on the surface. A similar observation was reported for the adsorption of acid red 88 on Iranian golden Sesamum indicum hull (19), Congo red on rice husk (42) and methylene blue on pineapple stem waste (43).

Considering kinetic data (Figures 9a-c), the adsorption capacity values obtained from pseudo-second-order model were more consistent with regression coefficients $\left(\mathrm{R}^{2}=0.957\right)$. In general, the pseudo-second-order kinetic model assumes that the adsorption process occurs on localized sites with no interaction between adsorbates and the maximum adsorption corresponding to a saturated monolayer of adsorbates onto the adsorbent surface. Furthermore, the rate of desorption is negligible compared to the rate of adsorption (41).

The $\Delta \mathrm{H}^{\circ}=41.181 \mathrm{~kJ} / \mathrm{mol}$ (Table 3 ) proves the endothermic 
nature of the adsorption process, and $\Delta \mathrm{H}^{\circ}$ value confirms the existence of a strong chemical force between dye and adsorbent molecules, indicating chemical adsorption. The negative value of $\Delta \mathrm{G}^{\circ}$ proves the spontaneous adsorption process. Positive values of $\Delta S^{\circ}$ show an association between the process of adsorption in this case and increased disorder in the surface of solid/solution (44). Other studies were reported for adsorption of Congo red and Eriochrome blue black $\mathrm{R}$ on carbon composite lignin-based adsorbent (45) and heavy metal ions on poly (amidoxime)/SiO2 (39) support our findings.

ANN model with 5, 12 and 1 neurons in input, hidden and output layer, respectively (Figure 10a, b), was performed in the studied ranges of the variables (Table 4). A learning rule was used to train the given data by adjustments of the correction weights through applying suitable algorithms, and the optimal weights was also determined (Table 5). The relative importance of input variables on the value of dye removal efficiency was calculated and the results showed that all of the variables have strong impacts on the dye removal efficiency (Table 6). It was confirmed by the result that the dye removal efficiency in this system was reproduced by neural network model, within the experimental ranges adopted in the fitting model (Figure 10c).

\section{Conclusion}

Surface modification of natural zeolite by a cationic surfactant (hexadecyl trimethyl ammonium bromide, HDTMA-Br) and its application for the removal of direct blue 129 were investigated. Surface properties of both modified and unmodified zeolites were evaluated by infrared spectroscopy and scanning electron microscopy (SEM) images. At dye concentration of $50 \mathrm{mg} / \mathrm{L}$, the optimum values for adsorbent and $\mathrm{pH}$ were 0.3 and $7 \mathrm{~g}$, respectively. With increasing the amount of adsorbent, due to the increased surface area of the adsorbent and more access to adsorption sites, the amount of dye removal was increased. Examining the effect of concentration showed that with increasing dye conce $\mathrm{n}$ tration, the adsorption volume by modified zeolite was reduced, since at increased dye concentration, repulsion occurred between anionic groups, preventing the adsorption of the dye by the adsorbent. By changing the $\mathrm{pH}$ value of the dye solution, no significant change was observed in the removal efficiency. The results showed that the adsorption of DB129 on modified zeolites complie d with the Langmuir isotherm. Also, the kinetics of dye adsorption on modified zeolites complied with ps e udo-secondorder kinetic model and evaluating the thermodynamic parameters indicates that the process was spontaneous and the reaction was endothermic. Mod e ling of the process using ANNs showed that this neural network can accurately model the experimental results. Comparison of the experimental results with the results of ANN showed that the correlation coefficient was equal to 0.951 . Acknowledgements

The authors would like to thank the Islamic Azad University, Ahar Branch for its financial support, the University of Tabriz and the Islamic Azad University, Miyaneh Branch, for all the supports provided. And special thanks to Mr. Pezhhanfar for English editing of the paper.

\section{Competing interests}

The authors declare that they have no competing interests.

\section{Ethical issues}

There were no ethical issues in the preparation of present article.

\section{Authors' contributions}

Authors were participated in all aspects of this research work, like data collection, analysis and interpretation and the manuscript approval.

\section{References}

1. Daneshvar N, Salari D, Khataee AR. Photocatalytic degradation of azo dye acid red 14 in water: investigation of the effect of operational parameters. J Photochem Photobiol A Chem 2003; 157(1): 111-6. doi: 10.1016/ S1010-6030(03)00015-7.

2. Engin AB, Ozdemir O, Turan M, Turan AZ. Color removal from textile dyebath effluents in a zeolite fixed bed reactor: determination of optimum process conditions using Taguchi method. J Hazard Mater 2008; 159(2-3): 348-53. doi: 10.1016/j.jhazmat.2008.02.065.

3. Armagan B, Turan M, Celik MS. Equilibrium studies on the adsorption of reactive azo dyes into zeolite. Desalination 2004; 170(1): 33-9. doi: 10.1016/j.desal.2004.02.091.

4. Qiu M, Qian C, Xu J, Wu J, Wang G. Studies on the adsorption of dyes into clinoptilolite. Desalination 2009; 243(1-3): 286-92. doi: 10.1016/j.desal.2008.04.029.

5. Fathima NN, Aravindhan R, Rao JR, Nair BU. Dye house wastewater treatment through advanced oxidation process using Cu-exchanged Y zeolite: a heterogeneous catalytic approach. Chemosphere 2008; 70(6): 1146-51. doi: 10.1016/j.chemosphere.2007.07.033.

6. Han R, Wang Y, Sun Q, Wang L, Song J, He X, et al. Malachite green adsorption onto natural zeolite and reuse by microwave irradiation. J Hazard Mater 2010; 175(1-3): 1056-61. doi: 10.1016/j.jhazmat.2009.10.118.

7. Rosales E, Pazos M, Sanroman MA, Tavares T. Application of zeolite-Arthrobacter viscosus system for the removal of heavy metal and dye: Chromium and Azure B. Desalination 2012; 284: 150-6. doi: 10.1016/j.desal.2011.08.049.

8. Han R, Zhang J, Han P, Wang Y, Zhao Z, Tang M. Study of equilibrium, kinetic and thermodynamic parameters about methylene blue adsorption onto natural zeolite. Chem Eng J 2009; 145(3): 496-504. doi: 10.1016/j.cej.2008.05.003.

9. Wang S, Peng Y. Natural zeolites as effective adsorbents in water and wastewater treatment. Chem Eng J 2010; 156(1): 11-24. doi: 10.1016/j.cej.2009.10.029. 
10. Alver E, Metin AU. Anionic dye removal from aqueous solutions using modified zeolite: adsorption kinetics and isotherm studies. Chem Eng J 2012; 200-202: 59-67. doi: 10.1016/j.cej.2012.06.038.

11. Jamil TS, Abdel Ghafar HH, Ibrahim HS, Abd El-Maksoud IH. Removal of methylene blue by two zeolites prepared from naturally occurring Egyptian kaolin as cost effective technique. Solid State Sciences 2011; 13(10): 1844-51. doi: 10.1016/j.solidstatesciences.2011.07.016.

12. Meshko V, Markovska L, Mincheva M, Rodrigues AE. Adsorption of basic dyes on granular activated carbon and natural zeolite. Water Res 2001; 35(14): 3357-66. doi: 10.1016/S0043-1354(01)00056-2.

13. Wang C, Li J, Wang L, Sun X, Huang J. Adsorption of Dye from Wastewater by Zeolites Synthesized from Fly Ash: Kinetic and Equilibrium Studies. Chinese Journal of Chemical Engineering 2009; 17(3): 513-21. doi: 10.1016/ S1004-9541(08)60239-6.

14. Wang S, Li H, Xu L. Application of zeolite MCM-22 for basic dye removal from wastewater. J Colloid Interface Sci 2006; 295(1): 71-8. doi: 10.1016/j.jcis.2005.08.006.

15. Salari D, Daneshvar N, Aghazadeh F, Khataee AR. Application of artificial neural networks for modeling of the treatment of wastewater contaminated with methyl tertbutyl ether (MTBE) by UV/H2O2 process. J Hazard Mater 2005; 125(1-3): 205-10. doi: 10.1016/j.jhazmat.2005.05.030.

16. Salari D, Niaei A, Khataee A, Zarei M. Electrochemical treatment of dye solution containing C.I. Basic Yellow 2 by the peroxi-coagulation method and modeling of experimental results by artificial neural networks. J Electroanal Chem 2009; 629(1-2): 117-25. doi: 10.1016/j. jelechem.2009.02.002.

17. Aleboyeh A, Kasiri MB, Olya ME, Aleboyeh H. Prediction of azo dye decolorization by $\mathrm{UV} / \mathrm{H} 2 \mathrm{O} 2$ using artificial neural networks. Dyes Pigm 2008; 77(2): 288-94. doi: 10.1016/j.dyepig.2007.05.014.

18. Jin X, Jiang MQ, Shan XQ, Pei ZG, Chen Z. Adsorption of methylene blue and orange II onto unmodified and surfactant-modified zeolite. J Colloid Interface Sci 2008; 328(2): 243-7. doi: 10.1016/j.jcis.2008.08.066.

19. Zarei M, Pezhhanfar S, Ahmadi Someh A. Removal of acid red 88 from wastewater by adsorption on agrobased waste material. A case study of Iranian golden Sesamum indicum hull. Environ Health Eng Manag 2017; 4(4): 195-201. doi: 10.15171/ehem.2017.27.

20. Tyagi B, Chudasama CD, Jasra RV. Determination of structural modification in acid activated montmorillonite clay by FT-IR spectroscopy. Spectrochim Acta A Mol Biomol Spectrosc 2006; 64(2): 273-8. doi: 10.1016/j. saa.2005.07.018.

21. Dawood S, Sen TK. Removal of anionic dye Congo red from aqueous solution by raw pine and acid-treated pine cone powder as adsorbent: equilibrium, thermodynamic, kinetics, mechanism and process design. Water Res 2012; 46(6): 1933-46. doi: 10.1016/j.watres.2012.01.009.

22. Moller MF. A scaled conjugate gradient algorithm for fast supervised learning. Neural Netw 1993; 6(4): 525-33. doi: 10.1016/S0893-6080(05)80056-5.

23. Alpat SK, Ozbayrak O, Alpat S, Akcay H. The adsorption kinetics and removal of cationic dye, Toluidine Blue $\mathrm{O}$, from aqueous solution with Turkish zeolite. J Hazard Mater
2008; 151(1): 213-20. doi: 10.1016/j.jhazmat.2007.05.071.

24. Wang S, Ariyanto E. Competitive adsorption of malachite green and $\mathrm{Pb}$ ions on natural zeolite. J Colloid Interface Sci 2007; 314(1): 25-31. doi: 10.1016/j.jcis.2007.05.032.

25. Feng Y, Yang F, Wang Y, Ma L, Wu Y, Kerr PG, et al. Basic dye adsorption onto an agro-based waste material--sesame hull (Sesamum indicum L.). Bioresour Technol 2011; 102(22): 10280-5. doi: 10.1016/j.biortech.2011.08.090.

26. Bhattacharyya KG, Sharma A. Kinetics and thermodynamics of methylene blue adsorption on Neem (Azadirachta indica) leaf powder. Dyes Pigm 2005; 65(1): 51-9. doi: 10.1016/j. dyepig.2004.06.016.

27. Wang $\mathrm{S}$, Zhu ZH. Characterisation and environmental application of an Australian natural zeolite for basic dye removal from aqueous solution. J Hazard Mater 2006; 136(3): 946-52. doi: 10.1016/j.jhazmat.2006.01.038.

28. Sohrabnezhad SH, Pourahmad A. Comparison adsorption of new methylene blue dye in zeolite and nanocrystal zeolite. Desalination 2010; 256(1-3): 84-9. doi: 10.1016/j. desal.2010. 02.009 .

29. Zupan J, Gasteiger J. Neural networks in chemistry and drug design. 2nd ed. Weinheim: Wiley- VCH; 1999.

30. Khataee AR, Fathinia M, Zarei M, Izadkhah B, Joo SW. Modeling and optimization of photocatalytic/photoassistedelectro-Fenton like degradation of phenol using a neural network coupled with genetic algorithm. J Ind Eng Chem 2014; 20(4): 1852-60. doi: 10.1016/j.jiec.2013.08.042.

31. Zarei M, Niaei A, Salari D, Khataee AR. Removal of four dyes from aqueous medium by the peroxi-coagulation method using carbon nanotube-PTFE cathode and neural network modeling. J Electroanal Chem 2010; 639(1-2): 167-74. doi: 10.1016/j.jelechem.2009.12.005.

32. Hornik K, Stinchcombe M, White H. Multilayer feedforward networks are universal approximators. Neural Netw 1989; 2(5): 359-66. doi: 10.1016/0893-6080(89)90020-8.

33. Akgul M, Karabakan A. Promoted dye adsorption performance over desilicated natural zeolite. Microporous Mesoporous Mater 2011; 145(1-3): 157-64. doi: 10.1016/j. micromeso.2011.05.012.

34. Ghobadi J, Arami M, Bahrami H. Modification of multiwalled carbon nanotubes and its application for removal of direct blue 86. Journal of Color Science and Technology 2013; 7(2): 103-12. [In Persian].

35. Kausar A, Iqbal M, Javed A, Aftab K, Nazli ZI, Bhatti $\mathrm{HN}$, et al. Dyes adsorption using clay and modified clay: A review. J Mol Liq 2018; 256: 395-407. doi: 10.1016/j. molliq.2018.02.034.

36. Tahir MA, Bhatti HN, Iqbal M. Solar red and brittle blue direct dyes adsorption onto Eucalyptus angophoroides bark: equilibrium, kinetics and thermodynamic studies. J Environ Chem Eng 2016; 4(2): 2431-9. doi: 10.1016/j. jece.2016.04.020.

37. Tahir N, Bhatti HN, Iqbal M, Noreen S. Biopolymers composites with peanut hull waste biomass and application for crystal violet adsorption. Int J Biol Macromol 2017; 94(Pt A): 210-20. doi: 10.1016/j.ijbiomac.2016.10.013.

38. Dogan M, Abak H, Alkan M. Adsorption of methylene blue onto hazelnut shell: kinetics, mechanism and activation parameters. J Hazard Mater 2009; 164(1): 172-81. doi: 10.1016/j.jhazmat.2008.07.155.

39. Gao B, Gao Y, Li Y. Preparation and chelation adsorption 
property of composite chelating material poly(amidoxime)/ $\mathrm{SiO} 2$ towards heavy metal ions. Chem Eng J 2010; 158(3): 542-9. doi: 10.1016/j.cej.2010.01.046.

40. Kitamura A, Hamamoto S, Taniike A, Ohtani Y, Kubota $\mathrm{N}$, Furuyama Y. Application of proton beams to radiationinduced graft polymerization for making amidoxime-type adsorbents. Radiat Phys Chem 2004; 69(2): 171-8. doi: 10.1016/S0969-806X(03)00439-0.

41. Shin KY, Hong JY, Jang J. Heavy metal ion adsorption behavior in nitrogen-doped magnetic carbon nanoparticles: isotherms and kinetic study. J Hazard Mater 2011; 190(1-3): 36-44. doi: 10.1016/j.jhazmat.2010.12.102.

42. Han R, Ding D, Xu Y, Zou W, Wang Y, Li Y, et al. Use of rice husk for the adsorption of Congo red from aqueous solution in column mode. Bioresour Technol 2008; 99(8):
2938-46. doi: 10.1016/j.biortech.2007.06.027.

43. Hameed BH, Krishni RR, Sata SA. A novel agricultural waste adsorbent for the removal of cationic dye from aqueous solutions. J Hazard Mater 2009; 162(1): 305-11. doi: $\quad 10.1016 /$ j.jhazmat.2008.05.036.

44. Karagozoglu B, Tasdemir M, Demirbas E, Kobya M. The adsorption of basic dye (Astrazon Blue FGRL) from aqueous solutions onto sepiolite, fly ash and apricot shell activated carbon: kinetic and equilibrium studies. J Hazard Mater 2007; 147(1-2): 297-306. doi: 10.1016/j. jhazmat.2007.01.003.

45. Wang X, Jiang C, Hou B, Wang Y, Hao C, Wu J. Carbon composite lignin-based adsorbents for the adsorption of dyes. Chemosphere 2018; 206: 587-96. doi: 10.1016/j. chemosphere.2018.04.183. 